\title{
Weighted Bankruptcy Rules and Transboundary Water Resources Allocation
}

\author{
Hojjat Mianabadi • Erik Mostert • Saket Pande • Nick van de Giesen
}

Received: 14 November 2014 / Accepted: 21 January 2015 /

Published online: 13 February 2015

(C) The Author(s) 2015. This article is published with open access at Springerlink.com

\begin{abstract}
One significant problem of transboundary river basins causing various challenges and disputes throughout the world is that because of increasing water resource variability and consumption, the water demand often exceeds water availability. Hence, one of the main challenges in transboundary river basin management is how to allocate the available water among the riparian states equitably and reasonably. In this study, we propose a novel weighted bankruptcy solution method to cope with the problem of demands or "claims" exceeding resources or "assets". Certain desirable key properties of the proposed method are provided. Furthermore, we investigate its application to the Tigris River, a shared river among Turkey, Syria and Iraq, as a real case. The available water is allocated under two different situations: homogeneous and heterogeneous group. We use the Shapley Value and compare the solution with other allocation methods applied in this study. The results suggest that this new rule may facilitate negotiation in solving conflict over the allocation of water in transboundary river basins.
\end{abstract}

Keywords Weighted bankruptcy rules · Transboundary water resources · Water allocation · Tigris River

\footnotetext{
H. Mianabadi $(\bowtie) \cdot$ E. Mostert $\cdot$ S. Pande $\cdot$ N. van de Giesen Department of Water Resources, Faculty of Civil Engineering and Geosciences, Delft University of Technology, Stevinweg 1, 2628 CN Delft, The Netherlands

e-mail: h.mianabadi@tudelft.nl

E. Mostert

e-mail: e.mostert@tudelft.nl

S. Pande

e-mail: s.pande@tudelft.nl

N. van de Giesen

e-mail: n.c.vandegiesen@tudelft.nl

H. Mianabadi

Tufts Institute of the Environment, Tufts University, Medford, MA 02155, USA
} 


\section{Introduction}

There are 276 transboundary river basins in the world share among 148 riparian countries (De Stefano et al. 2012). These shared natural resources among riparian countries can be a source of both conflict and cooperation (Mianabadi et al. 2014b). One significant problem of transboundary river basin management which has been causing various challenges and disputes throughout the world is that due to increasing water resource variability and consumption, the demands or claims of the riparian countries exceed the available water resources or assets. This presents the challenge how to allocate the available water resources among the countries in an "equitable" and "reasonable" way and which criteria and mechanisms to use for this purpose.

The language of equity has long been key to international environmental and water resources law (McIntyre 2013). It has been applied in several international conventions and declarations e.g. in the United Nations Environment Programme (UNEP 1978) as the key requirement in inter-state cooperation, Principle 3 of the 1992 Report of the United Nations Conference on Environment and Development: Rio Declaration on Environment and Development (Rio Declaration, 1992), the 1992 United Nations Framework Convention on Climate Change (UNFCCC, 1992), the 1992 Convention on Biological Diversity (CBD, 1992), the International Law Commission's 2001 Draft Articles on the Prevention of Trans boundary Harm from Hazardous Activities, and Articles 5 and 6 the United Nations Convention on the Law of the Non-Navigational Uses of International Watercourses (the UN Convention 1997) (McIntyre 2013). Among several international water laws and conventions, the Helsinki Rules (1966), the UN Watercourses Convention (1997), and the Berlin Rules (2004) are more well-known and reputed.

Equity, as the cornerstone of modern international water law (Fuentes 1997), has a key role to play in international water laws for shared water resources allocation. Efforts to find an internationally acceptable and comprehensive equitable water allocation mechanism for shared and transboundary river basins have not been successful yet (Swain 2001), and hence, each riparian country refers to the criteria and principles that support its claim most. In the Nile basin, for instance, which is shared among eleven riparian countries, Egypt and Sudan are the largest water consumers and their claims are disputed by the other riparians (Ansink 2009). Egypt defends its claim based on the principle of historical use and right, whereas Sudan, located upstream of Egypt, defends its claim by referring to the principle of equitable and reasonable utilization (Ansink 2009). So, a serious limitation of these laws and conventions is that they have not introduced an acceptable allocation mechanism to achieve an equitable and reasonable water allocation. Accordingly, Wolf (1999) notes that the central issue at the heart of the international water quantity conflicts is the fact that there are no internationally accepted attributes and mechanisms for equitable allocating shared water resources or their benefits.

One significant aspect neglected by many of those scholars arguing for equitable and reasonable water allocation in their studies is that even though they endeavour to maximize the net benefit from cooperative or non-cooperative games, the optimal solution does not mean equitable and reasonable allocation. According to Article 6 of the 1997 United Nations Convention on the Law of the Non-Navigational Uses of International Watercourses (UN Watercourses Convention, 1997), utilization of an international watercourse in an equitable and reasonable manner requires taking into account all relevant factors and circumstances, including the following: (a) geographic, hydrography, hydrological, climatic, ecological and other factors of a natural character; (b) the social and economic needs of the watercourse states concerned; (c) the population dependent on the watercourse in each watercourse State; (d) the effects of the use or uses of the watercourses in one watercourse State on other watercourse 
States; (e) existing and potential uses of the watercourse; (f) conservation, protection, development and economy of use of the water resources of the watercourse and the costs of measures taken to that effect; ( $g$ ) the availability of alternatives, of comparable value, to a particular planned or existing use. Accordingly, maximizing only the net monetary benefits from utilizing water for economic activities does not mean equitable and reasonable allocation. Moreover, it should be emphasized that equality does not always mean equity in water resource allocation.

The issues of cooperative vs. non-cooperative solutions to shared water resources allocation have been debated by scholars for many years. (Dinar et al. 1992; McCarthy et al. 2001; Pande and McKee 2007; Dinar and Nigatu 2013; Pande and Ertsen 2014). Some researchers argue that non-cooperative game theory solutions lead to overexploitation of the shared water resources and they are typically inefficient (Ambec and Ehlers 2008), whereas some others believe that there are some reasons for the players to prefer non-cooperation (Dinar and Nigatu 2013), for instance, high coordination cost associated with cooperation of large numbers of players (Just and Netanyahu 1998) or historical and cultural disputes among states. Recent literature on cooperative game theory distinguishes between games with transferable utility and games with non-transferable utility (Dinar et al. 1992). Bankruptcy theory is one of the applicable methods for conflict management in resources allocation problems. The aim of this method is a fair division of assets or a common resource $(E)$ among some creditors when their claims $(C)$ exceed $E$. This theory, a form of cooperative game theory method, provides solutions that are more useful than conventional cooperative game theory solutions when the information about utilities of stakeholders or their endowments is missing or unreliable (Zarezadeh et al. 2012).

Bankruptcy rules redistribute an asset $E$ when it is not sufficient to meet all claims $C$. Due to various interpretations of equity, several bankruptcy rules have been proposed. There are three general procedures to solve a bankruptcy problem (Herrero and Villar 2001): (1) dividing 'what is there' (awards) among claimants, (2) dividing 'what is not there' (loses or deficit) among agents and (3) both of them. An overview of bankruptcy rules is given by Thomson (2003, 2009). In addition to the proportional rule (PRO), there are some classical bankruptcy rules such as constrained equal awards (CEA), constrained equal losses (CEL), the Talmud rule (TAL), constrained egalitarian (CE), Adjust Proportional (AP), and Random arrival (RA) rule. PRO rule was already a favored rule of distribution among philosophers of ancient Greece, and even now is widely used in reallocation problems; for instance, it seems to be the principal rule behind the EU distribution of fishing Total Allowable Catch (TAC) and the Common European Fisheries Policy (Gallastegui et al. 2002). A comparative analysis of four classical solutions (PRO, CEA, CEL, and TAL) from an axiomatic viewpoint was provided in Herrero and Villar (2001). Ansink and Weikard (2012) present a class of sequential sharing rules (SSRs). Each rule in this class is based on a given bankruptcy rule, such as PRO, CEA or CEL.

Bankruptcy theory has been applied for numerous resource allocation problems. Ansink and Marchiori (2010), Ansink and Weikard (2012), and Mianabadi et al. (2014a) used it in water resources management. Zarezadeh et al. (2012) applied four bankruptcy rules including PRO, AP, CEL and CEA to suggest the most acceptable allocation scheme for different scenarios of future development and climate for Qezelozan-Sefidrood River Basin in Iran. They also proposed and applied bankruptcy optimization models to allocate water based on four bankruptcy rules with respect to time sensitivity of water deliveries during the planning horizon in this basin (Madani et al. 2014). To determine a fair resource allocation based on the legal status of the Caspian Sea, four bankruptcy rules were applied to reallocate oil and gas resources among the five littoral states (Sheikhmohammady and Madani 2008). The Talmud 
rule was applied in a water resource distribution problem by Li (2009). Xia and Cui (2009) also propose a water resource allocation mechanism encouraging improvement of water use efficiency and productivity based on an incentive mechanism combining of Data Envelopment Analysis (DEA) theory and Talmud rule as well as elimination mechanism. Gallastegui et al. (2002) applied bankruptcy theory to the distribution of a Total Allowable Catch (TAC) among the different countries exploiting the Northern European anglerfish fishery.

In many applications of resource allocation problems, the assumption symmetry between players seems unrealistic for the situation that is being modelled and the use of non-symmetric generalizations of the allocation method was developed in such cases (Kalai and Samet 1987). In shared water resources allocation problems, to apply several factors and circumstances mentioned in the Articles 6 of the UN Watercourses Convention 1997 for equitable and reasonable shared water allocation, sometimes we need to assign different weights to some factors e.g. the rate of population who depend on water or environmental crises in some parts of a shared basin. Weighted bankruptcy rules, in which the claims of different agents are given different weights according to their power or conditions of issue, can be used as an applicable allocation method. These methods have not been addressed extensively. They were studied in Lee (1994), Moulin (2000), Hokari and Thomson (2003) and Casas-Méndez et al. (2011). Lee (1994) discusses a weighted version of the constrained equal awards rule and develops a characterization of this rule based on consistency. Moulin (2000) surveyed the characterization of the weighted CEA and CEL rules. Hokari and Thomson (2003) studied the family of weighted Talmud rules. Casas-Méndez et al. (2011) give four axiomatic characterizations of the weighted constrained adjusted proportional (APRO) rule, the weighted CEA rule, the weighted CEL rule, and the weighted constrained proportional (PRO) rule.

An ordinary bankruptcy problem differs from a bankruptcy problem in river systems problems (Mianabadi et al. 2014a). First, in an ordinary bankruptcy problem claimants are characterized only by their claims, but in a river allocation problem they are characterized by their contribution as well as their claims. Secondly, the geographical position of agents is not important in ordinary bankruptcy problems. In river sharing problems this may be the case. One significant limitation of some of previously mentioned methods, such as Ambec's methods (Ambec and Sprumont 2002; Ambec et al. 2013), SSRs (Ansink and Weikard 2012), or Ambec and Ehlers's allocation method (Ambec and Ehlers 2008) is that agents should be ordered linearly along water resource. Thus, they are not applicable to reallocate complex multitributary transboundray river systems and other natural resources including lakes, groundwater aquifers, and shared sea resources. Another limitation of some other conventional methods such as PRO, CEA, and CEL rules is that they do not take into account the contribution that agents have made to $E$. This does not seem to be fair (cf. art. 6 UN Water courses Convention). In addition, sometimes we need to assign different weights to claimants according to conditions of issue.

Accordingly, in this paper, we develop a new weighted bankruptcy solution that agents' geographical location is not an issue. In addition, agents' contribution to total asset $(E)$ are considered in the final allocation. Reallocation of Tigris River water resources, as a shared river among Turkey, Syria, and Iraq, is used as an example to illustrate the application of the proposed solution to a real allocation problem. The available water of the Tigris River is allocated under two different situations: homogeneous and heterogeneous group (equal and unequal relative weights of states). The paper is arranged as follow. The new proposed solution is explained in the next section. In section 3, Tigris River reallocation is discussed. Section 4 concludes the paper. 


\section{Materials and Methods}

Consider a set $N$ of $n \leq 2$ agents with relative weights $w_{i}$, whose claims and contributions are $c_{i} \geq 0 ; \quad c=\left(c_{1}, \ldots, c_{n}\right)$ and $a_{i} \geq 0 ; \quad a=\left(a_{1}, \ldots, a_{n}\right)$, respectively. The objective of a bankruptcy rule is to specify the allocation of each agent which is denoted by $x_{i}=\psi_{i}(E, c, a) \geq 0$ such that (a) $\sum_{i=1}^{n} x_{i}=\sum_{i=1}^{n} a_{i}=E$ for all $i \in N$, (b) $0 \leq x_{i} \leq c_{i}$, and (C) $x_{i} \leq E, \forall i \in N$. Requirement (a), the sum of all allocations is equal to the available asset, imposes 'efficiency' (Ansink and Weikard 2012). Requirement (b) says that the allocation $x_{i}$ that each agent obtains is non-negative and not larger than his claim $c_{i}$ (Mianabadi et al. 2014a). This requirement imposes 'individual rationality' (Curiel et al. 1987). Requirement (c) which is a 'feasibility' constraint (Ansink and Weikard 2012) means that the allocation $x_{i}$ cannot exceed the total available asset.

As mentioned before, there are several bankruptcy rules for allocation problem including PRO, CEA and CEL.

1. Proportional (PRO) Rule is defined as follows:

$$
x_{i}^{P R O}=\rho c_{i} \quad \text { where } \quad \rho=\frac{E}{C}
$$

in which $C$ and $E$ are the total claim and the total asset, respectively. PRO allocates each agent the same proportion $\rho$ of its claims.

2. The constrained equal award (CEA) rule is defined as follows:

$$
x_{i}^{C E A}=\min \left(\lambda, c_{i}\right) \quad \text { where } \quad \sum_{i \in N} \min \left(\lambda, c_{i}\right)=E
$$

When CEA is used, all agents get the same allocation but never more than their claim.

3. The constrained equal losses (CEL) rule is defined as follows:

$$
x_{i}^{C E L}=\max \left(0, c_{i}-\lambda\right) \quad \text { where } \sum_{i \in N} \max \left(0, c_{i}-\lambda\right)=E
$$

CEL allocates each claimant a share of the asset such that their losses in comparison with their claims are equal, subject to no claimant receiving a negative allocation.

The CEA rule can be appropriate when distribution over agents is the primary concern and their claims only represent maximal aspirations; in contrast, the CEL rule can be appropriate when claims are realistic and have an objective basis (Herrero and Villar 2001). Agents with smaller claims get a relatively higher satisfaction of their claims using CEA rule, whereas CEL rule benefits agents with larger claims (Herrero and Villar 2001). The PRO rule can be placed in between these rules.

As mentioned earlier, weighted bankruptcy rules, in which the claims of different agents are given different weights according to their power or conditions of issue, have not been addressed extensively. Let $\psi_{i}(N, E, c, a, w)$ be a weighted bankruptcy problem with $i \in N$ claimants such that $w_{i}$ is positive weight of agent $i$. Here $w=\left(w_{1}, \ldots, w_{n}\right)$. 
The weighted CEA rule is given by as follows (Moulin 2000; Casas-Méndez et al. 2011):

$$
x_{i}^{W C E A}=\min \left(\lambda w_{i}, c_{i}\right) \quad \text { such that } \sum_{i \in N} \min \left(\lambda w_{i}, c_{i}\right)=E
$$

The weighted CEL rule is defined as follows (Moulin 2000; Casas-Méndez et al. 2011):

$$
x_{i}^{W C E L}=\max \left(0, c_{i}-\frac{\lambda}{w_{i}}\right) \quad \text { where } \sum_{i \in N} \max \left(0, c_{i}-\frac{\lambda}{w_{i}}\right)=E
$$

The weighted PRO rule is defined as follows (Casas-Méndez et al. 2011):

$$
x_{i}^{\text {WPROP }}=\min \left(\lambda w_{i} c_{i}, c_{i}\right) \quad \text { where } \sum_{i \in N} \min \left(\lambda w_{i} c_{i}, c_{i}\right)=E
$$

The weighted APRO rule is given by (Casas-Méndez et al. 2011):

$$
x_{i}^{\text {WAPROP }}=m_{i}(E, c, a, w)+\min \left(\lambda w_{i} c_{i}^{\prime}, c_{i}^{\prime}\right)
$$

where the minimum right of agent $i$ is defined as $m_{i}(E, c, a, w)=\max \left\{0, E-\sum_{j \in N \backslash\{i\}} c_{j}\right\}, E^{\prime}=$ $E-\sum_{i \in N} m_{i}(E, c, a, w), \quad c_{i}^{\prime}=\min \left\{c_{i}-m_{i}(E, c, a, w), E^{\prime}\right\}$ such that $\sum_{i \in N} \min \left(\lambda w_{i} c_{i}^{\prime}, c_{i}^{\prime}\right)=E^{\prime}$.

The limitations with most of previously mentioned bankruptcy rules is that they either do not consider the contribution $\left(a_{i}\right)$ that the agents make to the resource $(E)$ or some are appropriate only for linearly ordered agents.

The proposed rule is based on the principle that the difference between $C$ and $E$ should be divided inversely proportional to the contribution of each agent to $E$. In other words, the bigger their contribution, the smaller the difference between their claim and the allocation they get. So, the total deficit $(D)$ is denoted as follow:

$$
D=C-E
$$

which $C$ and $E$ are the total amount of claim and the asset or total resources, respectively.

The total deficit $(D)$ should be proportionally divided according to agents' contribution and its relative weight and subtracted from their claims. Thus, the deficit or loss of each agent $d_{i}^{w}$ is calculated as follow:

$$
d_{i}^{w}=\left\{\frac{1-\left(\frac{w_{i} a_{i}}{\sum_{i \in N} w_{i} a_{i}}\right)}{n^{-1}}\right\} * D \text { where } \sum_{i \in N} w_{i}=1 \text { such that } d_{i}^{w} \leq c_{i} .
$$

in which $c_{i}$ and $a_{i}$ are the claim and asset of agent $i . w_{i}$ is the relative weight of agent $i$ and $n$ is 
the number of agents and $D$ is the total deficit evaluated using equation 8 . The allocation of each agent $\left(x_{i}\right)$ is then calculated by $x_{i}=c_{i}-d_{i}$ or as follows:

$$
\psi_{i}\left(N, E, c_{i}, a_{i}, w_{i}\right)=c_{i}-\left[\frac{1-\left(\frac{w_{i} a_{i}}{\sum w_{i} a_{i}}\right)}{n-1} * D\right] ; 0 \leq x_{i} \leq c_{i}
$$

This method imposes 'anonymity' of the bankruptcy rule that says that for $\psi^{\prime}\left(N^{\prime}, E, c, a, w\right)$ where $N^{\prime}$ is any permutation of $N$, we have $\psi(N, E, c, a, w)=\psi^{\prime}\left(N^{\prime}, E, c, a, w\right)$ (Ansink and Weikard 2012). It stresses that any difference in allocation between downstream and upstream agents is not due to the preferential treatment of agents by a particular bankruptcy rule (Ansink and Weikard 2012). For $N=1$, we allow $x_{1}=E$ and $d_{1}=C-E$.

The merit of this method compared to the previously mentioned rules is that the position of agents is not important and it can be applied to other types of transboundary rivers and other natural resources including lakes, groundwater aquifers and shared sea resources. In addition, agents' contribution to total asset $(E)$ are considered in the final allocation. In an exceptional situation, if $d_{i}>c_{i}$ then $x_{i}=0$. For example, if $a_{i}=0$ and $c_{i}$ be small, $d_{i}$ will be greater than $c_{i}$. The water resources allocation of the Tigris River is used as a real case study to illustrate how to implement the proposed technique. It is noticeable to mention that we assume that all relevant effective factors including social, population, natural and ecological characters, economic and sustainable development criteria are considered in determining the demands of each riparian country. Moreover, political and military power of each state does not affect to overestimate the states' claims.

\section{Properties}

In this section, we provide certain desirable key properties of the proposed method. We use $\psi^{w}$ as shorthand for $\psi^{w}(N, E, c, a, w)$ Proof of some properties that seem to need be proved are presented in Appendix.

Feasibility The weighted rule $\psi^{w}$ satisfies feasibility, i.e. for all $(N, E, c, a, w)$ and for all $i \in N$, we have $\psi_{i}^{w}(N, E, c, a, w) \leq E$.

This property (cf.(Ansink and Weikard 2012)) says that no allocation of each agent can exceed the total available asset.

Efficiency The weighted rule $\psi^{w}$ satisfies efficiency, i.e. for all $(N, E, c, a, w)$ we have $\sum_{i \in}$ ${ }_{N} \psi_{i}^{w}(N, E, c, a, w)=E$.

This property (cf. (Thomson 2003)) says that the entire asset available should be allocated and the sum of all allocations is equal to the available asset.

Claim Boundedness The weighted rule $\psi^{w}$ satisfies claim boundedness, i.e. for all $(N, E, c, a, w)$ and for all $i \in N$ we have $\psi_{i}^{w}(N, E, c, a, w) \leq c_{i}$. 
This property (cf. (Thomson 2003)) says that no agent should receive more than his claim.

Equal Treatment of Equals A weighted rule $\psi^{w}$ satisfies equal treatment of equals if for all $(N$, $E, c, a, w)$, if $i, j \in N$ are such that $c_{i}=c_{j}, a_{i}=a_{j}$ and $w_{i}=w_{j}$, then $\psi_{i}{ }^{w}(N, E, c, a, w)=\psi_{j}{ }^{w}(N, E, c, a, w)$.

This property says that two agents with the same claims, the same contribution, and the same weights should be equally awarded.

Scale Invariance (in Assets and Claims) The weighted rule $\psi^{w}$ satisfies scale invariance (in assets and claims), i.e. for all $(N, E, c, a, w)$ and all $\lambda>0$, the equality $\psi^{w}(N, \lambda E, \lambda c, \lambda a$, $w)=\lambda \psi^{w}(N, E, c, a, w)$ holds.

This property (cf. (Herrero and Villar 2001)) says that the proportional change in assets and claims does not matter. It means that it does not distinguish analytically between a change of measurement units, for instance to divide one million cubic meter of water or to allocate one billion cubic meter of water.

Exclusion The weighted rule $\psi^{w}$ satisfies exclusion, i.e. for all $(N, E, c, a, w)$ and for any $i \in N$, such that $c_{i} \leq D / n$, where $D=\sum_{i \in N} c_{i}-E$ and $\frac{w_{i} a_{i}}{\sum_{i \in N} w_{i} a_{i}} \leq 1 / n$, the equality $\psi_{i}^{w}(N, E, c, a, w)=0$ holds.

This property (cf. (Herrero and Villar 2001)) says that when the agent $i$ 's claim is so small so it is less than the average deficit and his relative contribution of assets is less than $1 / n$, then he gets nothing.

Composition (Young 1988) The weighted rule $\psi^{w}$ satisfies composition, i.e. for all $(N, E, c, a, w)$ and all $i \in N$ and $E^{\prime}, E^{\prime \prime}$ such that $E^{\prime}+E^{\prime \prime}=E, \quad E^{\prime}=\sum_{i \in N} a_{i}^{\prime}, E^{\prime \prime}=\sum_{i \in N} a_{i}^{\prime \prime}$, and $a_{i}=a_{i}^{\prime}+a_{i}^{\prime \prime}$, and the individual assets are proportional to $E^{\prime \prime} / E^{\prime}$, i.e. $\frac{a_{i}^{\prime \prime}}{a_{i}^{\prime}}=\frac{E^{\prime \prime}}{E^{\prime}}, \forall i \in N$, the equality $\psi^{w}(N, E, c$, $a, w)=\psi^{w}\left(N, E^{\prime}, c, a, w\right)+\psi^{w}\left\{N, E^{\prime \prime}, c-\psi^{w}\left(N, E^{\prime}, c, a, w\right), a, w\right\}$ holds.

This property says that the allocation problem can also be solved as the sum of two or more partial allocation problems.

Composition from Minimal Right (Curiel et al. 1987) ${ }^{1}$ The weighted rule $\psi^{w}$ satisfies composition from minimal rights, i.e. for all $(N, E, c, a, w)$ and under the assumption that reduction in total assets by $\sum_{i \in N} m_{i}(E, c)$ scales down individual assets by the same factor, i.e. the new set of assets are $a^{m}=\left(a_{1}^{m}, a_{2}^{m}, . ., a_{i}^{m}, ., a_{n}^{m}\right)$, where $a_{i}^{m}=\gamma a_{i}$ and $\gamma=\left[E-\sum_{i \in N} m_{i}(E\right.$, $c)] / E$, the equality $\psi^{w}(N, E, c, a, w)=m(E, c)+\psi^{w}\left(N, E-\sum_{i \in N} m_{i}(E, c), c-m(E, c), a^{m}\right.$, w) holds.

This property which is a variant of composition property (Herrero and Villar 2001) respects the minimal rights of agents.

\footnotetext{
${ }^{1}$ The property is called 'minimal rights property' in Curiel et al. (1987). Thomson (2003) and Dagan (1996) refer to it as 'Minimal rights first' and ' $v$-separability', respectively. Gallastegui et al. (2002) state this property under the name of 'composition up from minimal rights'.
} 
Order Preservation of Awards The weighted rule $\psi^{w}$ satisfies order preservation of awards, i.e. for all $(N, E, c, a, w)$, and $i, j \in N$ such that $c_{j} \geq c_{i}, a_{i}=a_{j}$ and $w_{i}=w_{j}$, the inequality $\psi_{j}{ }^{w}(N, E, c, a, w) \geq \psi_{i}{ }^{w}(N, E, c, a, w)$ holds.

This property (cf.(Thomson 2003)) says that the rule should respect the ordering of claims such that if agent $j$ 's claim is at least as large as agent $i$ 's claim, the former should receive at least as much as the latter.

Order Preservation of Losses The weighted rule $\psi^{w}$ satisfies order preservation of losses, i.e. for all $(N, E, c, a, w)$, and $i, j \in N$ such that $c_{j} \geq c_{i}, \quad a_{i}=a_{j}$ and $w_{i}=w_{j}$, the equality $d_{j}{ }^{w}(N, E, c, a, w)=d_{i}{ }^{w}(N, E, c, a, w)$ holds, where $d_{i}{ }^{w}(N, E, c, a, w)=c_{i}-\psi_{i}{ }^{w}$ $(N, E, c, a, w)$.

This property (cf.(Thomson 2003)) says that the rule should respect the ordering of claims and awards such that if agent $j$ 's claim is at least as large as agent $i$ 's claim (and if their weighted assets are equal), the former should lose at least as much as the latter.

Order Preservation Under Claims Variations The weighted rule $\psi^{w}$ satisfies order preservation under claims variations, i.e. for all $\left(N, E, c^{\prime}, a, w\right)$ and $(N, E, c, a, w)$ and for any $k \in N$ with $C$ $'=\left(C_{k}^{\prime}, C_{-k}\right)$ and $c_{k}^{\prime}<c_{k}$, and $i, j \in N$ in $N-\{k\}$ with $c_{j} \geq c_{i}$, the equality $\psi_{j}{ }^{w}\left(N, E, c^{\prime}, a, w\right)-\psi_{j}{ }^{w}$ $(N, E, c, a, w)=\psi_{i}^{w}\left(N, E, c^{\prime}, a, w\right)-\psi_{i}^{w}(N, E, c, a, w)$ holds.

This property (cf.(Bosmans and Lauwers 2011)) says that if the claim of some individual decreases, one agent with the greater claim still obtains a larger gain than the other. It then follows from order preservation of awards that the agent out of the first two with a larger claim receives a larger award.

Super Modularity The weighted rule $\psi^{w}$ satisfies super modularity, i.e. given two problems $(N$, $\left.E^{\prime}, c, a^{\prime}, w\right)$ and $(N, E, c, a, w)$ such that $\sum_{i \in N} c_{i} \geq E^{\prime}>E$, and for any $i, j \in N$ such that $c_{j} \geq c_{i}, a_{i}=a_{j}$ and $w_{i}=w_{j}$, and the ratio of an individual's asset in the two problems is proportional to $E^{\prime} / E$, i.e. $\frac{a_{i}^{\prime}}{a_{i}}=\frac{E^{\prime}}{E}, \forall i \in N$, the equality $\psi_{j}{ }^{w}\left(N, E^{\prime}, c, a^{\prime}, w\right)-\psi_{j}{ }^{w}(N, E, c, a, w)=\psi_{i}{ }^{w}\left(N, E^{\prime}, c, a^{\prime}, w\right)-$ $\psi_{i}^{w}(N, E, c, a, w)$ holds.

This property says that if total assets increase due to proportionate increase in individual assets, an agent with a greater claim receives no less share of the increment than the other (Dagan et al. 1997).

Claims Monotonicity The weighted rule $\psi^{w}$ satisfies claims monotonicity, i.e. for all $(N, E, c, a$, $w)$, and any $i \in N$ such that $c_{i}^{\prime}>c_{i}$, the inequality $\psi_{i}^{w}\left(N, E,\left(c_{i}^{\prime}, c_{-i}\right), a, w\right) \geq \psi_{i}^{w}(N, E, c, a, w)$ holds.

This property says that if an agent's claim increases, he should not be awarded a smaller quota.

Resource Monotonicity The weighted rule $\psi^{w}$ satisfies resource monotonicity, i.e. for all $(N, E, c, a, w)$, and for all $i \in N$ such that $a_{i}^{\prime}>a_{i}$, the inequality $\psi^{w}\left(N, E^{\prime}, c,\left(a_{i}^{\prime}, a_{-i}\right)\right.$, $w) \geq \psi^{w}(N, E, c, a, w)$. 
This property says that if individual assets of all the agents increase, each agent should receive at least as much as he did initially.

Linked Monotonicity The weighted rule $\psi^{w}$ satisfies linked monotonicity, i.e. for all (N,E,c,a, $w)$ and $\alpha \in R_{+}$, and a related problem $\left(N, E+\alpha,\left(c_{i}+\alpha, c_{-i}\right), a^{\prime}, w\right)$ where $\sum_{i \in N} a_{i}^{\prime}=E+\alpha$ is not due to the increase in $i$ 's asset but in someone else's asset, i.e. $a^{\prime}=\left(a_{1}+\alpha_{1}, a_{2}+\alpha_{2}, \ldots, a_{i}, \ldots, a_{n}+\alpha_{n}\right)$ such that $\sum_{j \in M\{i\}} \alpha_{j}=\alpha$, the inequality $\psi_{i}^{w}\left(N, E+\alpha,\left(c_{i}+\alpha, c_{-i}\right), a^{\prime}, w\right)-\psi_{i}^{w}(N, E, c, a, w) \leq \alpha$ holds.

This property says (cf.(Ansink and Weikard 2012)) that no agent's outcome should increase by more than $\alpha$, if this agent's asset and claim increase by the same amount $\alpha$.

Limited Consistency The weighted rule $\psi^{w}$ satisfies linked consistency, i.e. for all $(N, E, c, a, w)$, a bankruptcy problem involving $\mathrm{n}$ agents, and $\left(N+1, E,\left(0, c_{1}, c_{2}, \ldots, c_{n}\right),\left(0, a_{1}, a_{2}, \ldots, a_{n}\right), w\right)$, a bankruptcy problem involving $\mathrm{n}+1$ agents, the following inequality holds, $\psi^{w}\left(N+1, E,\left(0, c_{1}, c_{2}, \ldots, c_{n}\right),\left(0, a_{1}, a_{2}, \ldots, a_{n}\right), w\right)=\left(0, \psi^{w}(N, E, c, a, w)\right)$.

This property says (cf.(Bosmans and Lauwers 2011)) that adding an agent with a zero claim and zero asset does not change the awards of the agents already present.

Path Independence (Moulin 1987) The weighted rule $\psi^{w}$ satisfies path independence, i.e. if the individual assets in the two problems $(N, E, c, a, w)$ and $\left(N, E^{\prime}, c, a^{\prime}, w\right)$ are proportional to $E^{\prime} / E$, i.e. $\frac{a_{i}^{\prime}}{a_{i}}=\frac{E^{\prime}}{E}, \forall i \in N$ such that $E^{\prime} \geq E$, then the equality $\psi^{w}(N, E, c, a, w)=\psi^{w}\left(N, E, \psi^{w}\left(N, E^{\prime}, c, a^{\prime}, w\right), a, w\right)$ holds.

This property applies when after solving a problem $\left(E^{\prime}, c\right)$ it turns out that the actual worth of the $E$ falls less of what was expected (Herrero and Villar 2001).

\section{Case Study}

One of the main quantitative issues of water resources is that total claims of water users and stakeholders are higher than available water, and this type of situation can be characterized as a bankruptcy problem. The Euphrates-Tigris Rivers (Fig. 1), called sometimes the 'Twin Rivers', are the first and second longest rivers in southwest Asia (MacQuarrie 2004). This basin is an international basin with a total area of $879,790 \mathrm{~km}^{2}$ shared among Iraq (46 percent), Turkey (22 percent), the Islamic Republic of Iran (19 percent), the Syrian Arab Republic (11 percent), Saudi Arabia (1.9 percent) and Jordan (0.03 percent) (Lehner et al. 2008). The Islamic Republic of Iran contributes only to the Tigris, and Saudi Arabia and Jordan contributes only to the Euphrates. $98 \%$ of Iraq's water supply is provided by the Euphrates-Tigris rivers and for Syria, the Euphrates supplies $86 \%$ of its water resources and provides $50 \%$ of its domestic water demands (Zawahri 2006).

From 1970 until 1992 the three main riparian states (Turkey, Syria, and Iraq) held trilateral meetings to reach an agreement, but they faced several obstacles during the negotiations (Zawahri 2006). In spite of these obstacles, they signed several treaties and protocols to share the rivers such as the 1946 Treaty of Friendship and Neighbourly Relations among Turkey and Iraq, the 1987 protocol between Turkey and Syria, and the 1996 agreement between Iraq and Syria. The construction of the major development project known as the Southeastern Anatolia Project or Guneydogu Anadolu Projesi (GAP) of Turkey has increased dispute among the 


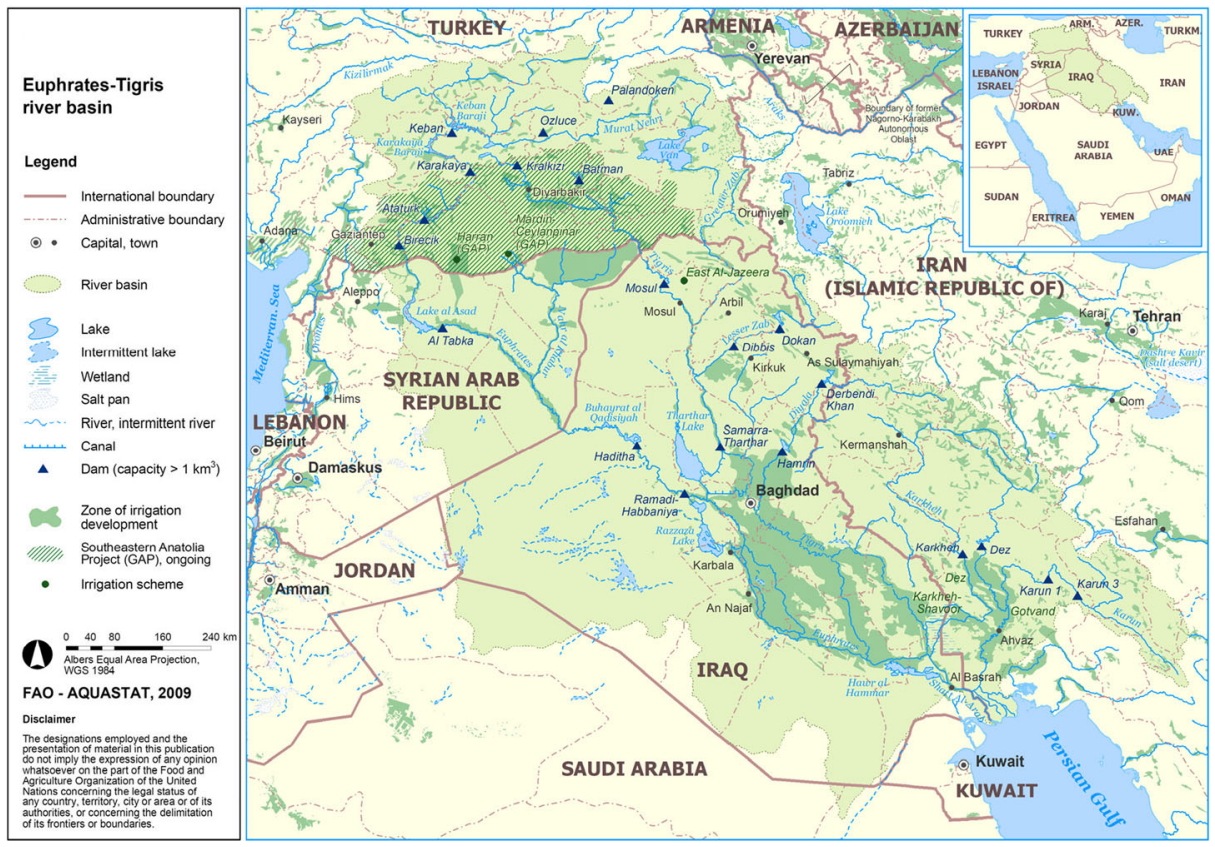

Fig. 1 Euphrates-Tigris- river basin. (adopted from (FAO-AQUASTAT 2009))

riparians since the early 1970s (Kolars 1994; Zawahri 2006; Zentner 2010). The GAP is expected to generate 7500 megawatts of electricity from 22 dams and irrigate 1.7 million hectares of land (Altinbilek 2004) that are expected to consume $52 \%$ of the water of the Euphrates and $14.1 \%$ of the Tigris (Tomanbay 2000). For more details about this project, see (Bagis 1989; Kolars and Mitchell 1991; Bilen 1994; Kolars 1994; Altinbilek 1997, 2004). Political disputes among the riparian states lead to serious tensions among them to the point that, in 1975, Syria and Iraq came very close to a full-scale war when Syria blocked the water flow of the Euphrates River (Schulz 1995).

The Tigris River rising in eastern Turkey flows through the country until the border city of Cizre. Forming the border between Turkey and the Syria over a short distance, only $32 \mathrm{~km}$, it crosses into Iraq at Faysh Khabur. The Tigris River is $1850 \mathrm{~km}$ long, with $400 \mathrm{~km}$ in Turkey, $32 \mathrm{~km}$ on the border between Turkey and the Syria and $1418 \mathrm{~km}$ in Iraq. Twelve percent of the Tigris Basin lies in Turkey, 0.2 percent in the Syria, 54 percent in Iraq and 34 percent in the Islamic Republic of Iran (FAO-AQUASTAT 2009). Within Iraq, there are several tributaries flowing into the river coming from the Zagros Mountains in the east: the Greater Zab, the Lesser Zab, the Al-Adhaim or Nahr Al Uzaym, the Diyala, the Nahr at Tib, and the Karkheh (FAO-AQUASTAT 2009). As Turkey, Syria and Iraq are more dependent on the Euphrates than the Tigris, they have developed it extensively, resulting in water scarcity so that this river fails to carry enough water to meet all demands (Zawahri 2006).

To apply the proposed bankruptcy rule, information on the water contribution and demands of riparian states is needed. The key to be used for calculating the available renewable water in a shared river basin among riparian countries is open to serious debate (Savenije and van der Zaag 2000). Several scholars have studied the water contribution, irrigable lands and water demand as well as the hydro-policy of each riparian country for both the Euphrates and Tigris rivers. It is estimated that Turkey provides $89 \%$ of the annual water volume of the Euphrates 
River, whereas Syria's contribution is only $11 \%$ and Iraq's contribution rate is none. While these rates for Tigris River for Turkey, Iraq, the Islamic Republic of Iran and Syria are 52, 38, 10, and $0 \%$ of the annual flow, respectively (Kaya 1998; Lupu 2002; Zawahri 2006; Kucukmehmetoglu 2009). However, some scholars (MacQuarrie 2004; Altinbilek 2004) present different riparian contribution rates. For instance, they argue that Turkey contributes about $98 \%$ to the Euphrates. Data on the water demand of each riparian country are available in (Kliot 1994; Kolars 1994; Altinbilek 1997; Beaumont 1998; Ibrahim and Sonmez 2002; Kucukmehmetoglu 2009). Different studies provide different water demand for riparian states because it is extremely difficult to obtain accurate statistics as to the area of irrigated land in riparian states and to predict the maximum evaporation losses for all the reservoirs in the basin (Beaumont 1998). Ibrahim and Sonmez (2002) mention the total demand on the Tigris River as $54470 \mathrm{MCM} / \mathrm{yr}$, Kolars (1994) argues it to be $35900 \mathrm{MCM} / \mathrm{yr}$, Kliot (1994) mentions 47700 MCM/yr, and Altinbilek (1997) evaluates it at about $39900 \mathrm{MCM} / \mathrm{yr}$. Beaumont (1998) revised the previous studies and estimates the minimum and maximum water demand of riparian states on the Tigris river to be about 44400 and $68300 \mathrm{MCM} / \mathrm{yr}$, respectively. The data used to allocate the water are summarized in Table 1.

As Table 1 shows, the total claim $(C)$ is $12 \%$ more than the available water $(E)$. We allocate the available water under two different situations: equal weights (homogeneous group) and different relative weights (heterogeneous group) of riparian states. For the first situation, we consider the equal relative weights for states and reallocate this limited resource between the riparian states using four bankruptcy rules (PRO, CEA, CEL, and the proposed method). The results are shown in Table 2. $p_{i}$ is the proportion of agent $i$ 's claim which is allocated to him $\left(x_{i}\right.$ $\left./ c_{i}\right)$.

It must be recognized that in this study, the weight of states differs with political and military power. If we apply the political or military power in allocation, it may result in hydrohegemony. This relative weight can be determined based on population size of riparian countries, catchment area occupied by each state, water and environment crisis in riparian countries, and etc. In this study, we assume these weights according to environmental crisis in the basin. Water crisis in downstream countries is more serious than upstream (Beaumont 1998). The negative ecological and environmental impacts of upstream infrastructures will probably be greatest in the lower part of the basin in the wetlands of Shatt el-Arab which are one of the world's great wetlands and that the drainage of this eco-system may damage biodiversity (Beaumont 1998). Moreover, the Turkish government will have substantial control over the flows of the two rivers when all the reservoirs on these rivers have been completed in the early years (Beaumont 1998). For instance, the capacity of active or usable storage of all the reservoirs which have been built or planned on the Euphrates River by

Table 1 Contribution and water demand $(\mathrm{MCM} / \mathrm{y})$ of riparian states on the Tigris River

\begin{tabular}{llll}
\hline Riparian & $\begin{array}{l}\text { Composition } \\
\text { of length } \\
\text { (Kliot 1994) }\end{array}$ & $\begin{array}{l}\text { Contribution of flow (MCM/yr and } \\
\text { percent of total flow) (Kaya 1998; } \\
\text { Lupu 2002; Zawahri 2006; } \\
\text { Kucukmehmetoglu 2009) }\end{array}$ & $\begin{array}{l}\text { Water demand and claim (MCM/yr) } \\
\text { (lbrahim and Sonmez 2002) }\end{array}$ \\
\hline Turkey & $400 \mathrm{~km} \mathrm{(22 \% )}$ & $25,240(52 \%)$ & 6870 \\
Syria & $32 \mathrm{~km} \mathrm{(1 \% )}$ & $0(0 \%)$ & 2600 \\
Iraq & $1418 \mathrm{~km}(77 \%)$ & $23,430(48 \%)^{\mathrm{a}}$ & 45,000 \\
Total & $1850 \mathrm{~km}(100 \%)$ & $48,670(100 \%)$ & $54,470(112 \%)$ \\
\hline
\end{tabular}

${ }^{\text {a }}$ The contribution of Iraq and Iran is 38 and $10 \%$, respectively 
Table 2 Reallocation of riparian states on the Tigris River (MCM/y) with equal and different weights

\begin{tabular}{|c|c|c|c|c|c|c|c|c|c|c|c|c|c|}
\hline \multirow[t]{2}{*}{$\begin{array}{l}\text { Relative } \\
\text { weights }\end{array}$} & \multirow[t]{2}{*}{ Riparian } & \multicolumn{3}{|l|}{ PRO } & \multicolumn{3}{|l|}{ CEA } & \multicolumn{3}{|l|}{ CEL } & \multicolumn{3}{|c|}{$\begin{array}{l}\text { The proposed } \\
\text { approach }\end{array}$} \\
\hline & & $x_{i}$ & $d_{i}$ & $p_{i}$ & $x_{i}$ & $d_{i}$ & $p_{i}$ & $x_{i}$ & $d_{i}$ & $p_{i}$ & $x_{i}$ & $d_{i}$ & $p_{i}$ \\
\hline \multirow{3}{*}{$\begin{array}{l}\text { Equal } \\
\text { rela- } \\
\text { tive } \\
\text { weig- } \\
\text { hts }\end{array}$} & Turkey & 6140 & 730 & $89 \%$ & 6870 & 0 & $100 \%$ & 4937 & 1933 & $72 \%$ & 5330 & 1540 & $78 \%$ \\
\hline & Syria & 2320 & 280 & $89 \%$ & 2600 & 0 & $100 \%$ & 667 & 1933 & $26 \%$ & 0 & 2600 & $0 \%$ \\
\hline & Iraq & 40,210 & 4790 & $89 \%$ & 39,200 & 5800 & $87 \%$ & 43,067 & 1933 & $96 \%$ & 43,340 & 1660 & $96 \%$ \\
\hline \multirow{3}{*}{$\begin{array}{l}\text { Different } \\
\text { rela- } \\
\text { tive } \\
\text { weig- } \\
\text { hts }\end{array}$} & Turkey & 2089 & 4781 & $30 \%$ & 6870 & 0 & $100 \%$ & 3598 & 3272 & $52 \%$ & 4397 & 2473 & $64 \%$ \\
\hline & Syria & 1581 & 1019 & $61 \%$ & 2600 & 0 & $100 \%$ & 964 & 1636 & $37 \%$ & 0 & 2600 & $0 \%$ \\
\hline & Iraq & 45,000 & 0 & $100 \%$ & 39,200 & 5800 & $87 \%$ & 44,108 & 892 & $98 \%$ & 44,273 & 727 & $98 \%$ \\
\hline
\end{tabular}

Turkey is 1.38 times the annual discharge of the river that means this state can easily regulate the flow of the river (Beaumont 1998). Table 2 shows the results of allocation using four weighted bankruptcy rules (WPRO, WCEA, WCEL, and the proposed method), assuming that the relative weights of states as $0.55,0.3$, and 0.15 for Iraq, Syria, and Turkey, respectively. However, there is no doubt that the reliable relative weight of states should be evaluated scientifically and comprehensively using studies like those have been carried on for determining water demand of states. Other values for the weights may of course be considered or negotiated.

\section{Results and Discussion}

Table 2 shows and compares the allocation of states with equal and unequal relative weights using the four bankruptcy rules: PRO, CEA, CEL and the proposed rule. Generally, as mentioned before, the results of the PRO, CEA and CEL rules may not be considered equitable by many agents in shared water allocation because they do not consider the contribution of states to supply total flow. For instance, assume a water allocation problem among four riparians whom contributions and claims are $a=(300,400,600,700)$ and $c=(500,700,300$, $1000)$, respectively. The total contribution and claim are $E=2000$ and $C=2500$. Using PRO rule their allocation are $x_{i}=(400,560,240,800)$. If the contributions of agents change into $a^{\prime}=$ $(500,100,200,1200)$ and their claims do not change, $c^{\prime}=(500,700,300,1000)$; the results remain constant whereas their contribution have changed considerably. While CEA rule favours agents with smaller claims such as Syria, CEL rule agents with larger claims such as Iraq (cf. (Herrero and Villar 2001; Ansink and Marchiori 2010)). The proposed method clearly favours countries with a large contribution to the water resources such as Turkey and Iraq; the allocation of Syria in this case is zero. This may not be considered equitable and reasonable and certainly will not be accepted by Syria. It suggests that the way in which the countries' contributions are taken into account may be refined.

Like non-weighted cases, the weighted CEA rule considers claims as upper bounds and agents with small claims are benefit, whereas the weighted CEL rule interprets as fundamental rights or vital necessities and prefers agents with big claims (Casas-Méndez et al. 2011). Hence, the results of the weighted CEA and classical CEA are equal. But the results of the 
weighted PRO, CEL and the proposed method in contrast with classical ones are different and reveals the impacts of relative weights of states on the final allocation. As can be seen in this Table, assigning the relative weights decreases the allocation of Turkey and increases the portion of Iraq. As Casas-Méndez et al. (2011) argue, the weighted CEA rule meet the full claim of agent whose claim is smaller than the proportional division of assets with respect to weights whereas the weighted CEL rule gives nothing to the agent whose claim is so small which does not reach the proportional division of loss with respect to weights. The weighted PRO rule lies between these rules.

The main advantage of the proposed method compared with conventional one is that it allows to consider the contribution rate of states as an important factor as well as their relative weights, which may facilitate negotiations among riparian countries. It is hard to tell whether the different allocations are efficient. Not according to the Pareto criterion because there are always losers, but possibly according to the Kaldor-Hicks criterion. This would require much more research on the economic, political, social, and environmental benefits of water use in the different countries. Introducing international water trading between the states might in theory improve allocative efficiency, but this is politically not feasible, if only because there is no agreement on initial water rights.

\subsection{Shapley Results}

We demonstrate the use of cooperative game theory methods in the Tigris River. We use the Shapley Value (Shapley 1953) and compare the solution with other allocation methods applied in this study. The Shapley value prescribes a payoff to each player that is the average marginal worth of that player to all the coalitions in which he or she can participate (Shapley 1953). This method satisfies the Core conditions, namely individual rationality, group rationality, and efficiency (Dinar and Nigatu 2013).

$$
\psi_{i}(S, \nu)=\sum_{\substack{s \subseteq S \\ i \in s}} \frac{(|s|-1) !(n-|s|)}{n !}[\nu(s)-\nu(s /\{i\})] \quad \text { for all } \quad i=1, \quad \ldots, n
$$

where, $\psi_{i}(S, \nu)$ is the Shapley allocation to player $i, S$ is set of all possible coalitions that contains player $i, n$ is the number of players in the coalition, $s$ is any coalition, $\nu(s)$ is the characteristic function of coalition $s,|\mathbf{s}|$ is the number of elements in $s$ and $\nu(s /\{i\})$ is the characteristic function of coalition $s$ without $i$. The Shapley Value for bankruptcy games can be computed according to the following procedure (Gallastegui et al. 2002). Lining up the agents in some random order, start with the first agent and give each agent his entire claim until total assets $E$ are exhausted. All orders are equally likely, and the Shapley Value allocates the average payment over all possible orders to each country (Gallastegui et al. 2002). Table 3 illustrates and gives the resulting water allocation solution using the Shapley Value method. $p_{i}$ for Turkey, Syria, and Iraq are 65, 67, and $95 \%$, respectively. $p_{i}$ is the proportion of agent $i$ 's claim which is allocated to $\operatorname{him}\left(x_{i} / c_{i}\right)$.

Like in other river basins, climate change can have undesirable effects on this basin located at the same latitude with the Mediterranean Basin (Kucukmehmetoglu 2009). Increased temperature and evapotranspiration and reduced precipitation may result in considerable changes in river runoff. It is predicted that runoff will decrease in the range of 5-40 percent for a majority of the basin for the period 2090-2099 relative to 1980-1999 (Granit and Joyce 
Table 3 Reallocation of riparian states on the Tigris River (MCM/y) using the Shapley value

\begin{tabular}{llll}
\hline Ordering & T & S & I \\
\hline TSI & 6870 & 2600 & 39200 \\
TIS & 6870 & 0 & 41,800 \\
STI & 6870 & 2600 & 39,200 \\
SIT & 1070 & 2600 & 45,000 \\
ITS & 3670 & 0 & 45,000 \\
IST & 1070 & 2600 & 45,000 \\
Total & 26,420 & 10,400 & 255,200 \\
Average $\left(x_{i}\right)$ & 4403 & 1733 & 42,533 \\
\hline
\end{tabular}

2012). Therefore, for further studies, it is proposed to consider the impact of climate change on the total flow and contribution rate of states to allocate the shared water among states according to different schemes. It can potentially decrease future conflict over the negative aspects of climate change. However, other measures will be required as well, such as increasing water use efficiency, improving water resource management (Granit and Joyce 2012).

It should be stressed that transboundary water allocation problems are complex; thus, we cannot argue that this proposed rule will be able to tackle all issues of shared water resources allocation throughout the world. People living in different regions tend to view water differently, so their appreciation of the resource and the values attributed to the various functions of the water as a result of cultural, climatic and economic circumstances (Savenije and van der Zaag 2000).

\section{Conclusions}

In this paper, the application of bankruptcy rules for conflict management of transboundary rivers is surveyed and we developed a new weighted bankruptcy solution for transboundary water resources allocation. The main feature of this rule is that the assets are allocated with respect to agents' contribution to the total resources and their relative weights. Moreover, we used the water resources allocation problem of the Tigris River as a real case in two different situations (homogeneous and heterogeneous group) to illustrate the application of the proposed method in the water resources allocation problems. We compared the proposed method with three alternative bankruptcy rules (PRO, CEA, and CEL) and weighted rules to transboundary river resources allocation problem. Due to lack of data, we assumed the relative weights of states with respect to two characteristics. Clearly, it is an issue to determine the real relative weights of riparian states in which needs to be carried on by further studies. This method can help policy makers to facilitate negotiation in managing conflict and dispute over water resources allocation problems. It is a tool to create more options that may assist riparian countries when negotiate tediously. However, some fine-tuning may still be necessary. Further studies may address the limitations of this study and consider some additional influential factors such as the impacts of climate change, reliable relative weights of states, and socio-political aspects of the basin as well as the effects of external powers. 


\section{Appendix: Proofs}

In this section, we prove some of the properties.

(a) Exclusion

Since $\sum_{i} w_{i} a_{i} a_{i} \leq 1 / n$, we have $\psi_{i}^{w}(N, E, c, a, w)=c_{i} \frac{\left[1-\frac{w_{i} a_{i}}{\sum_{j \in N} w_{j} a_{j}}\right]}{n-1} \leq \frac{D}{n}-$

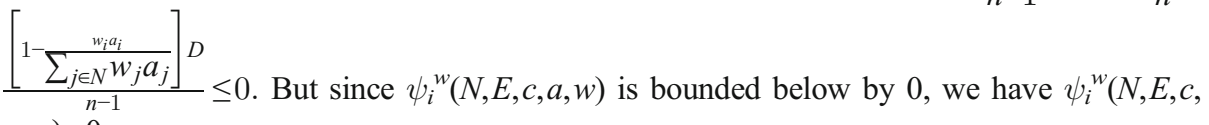
$a, w)=0$.

(b) Composition from Minimal Right

Since $\psi_{i}^{w}\left(N, E-\sum_{i \in N} m_{i}(E, c), c-m(E, c), a^{m}, w\right)=c_{i}-m_{i}(E, c)-d_{i}$, we have for all $i \in N$, $\psi_{i}^{w}\left(N, E-\sum_{i \in N} m_{i}(E, c), c-m(E, c), a^{m}, w\right)+m_{i}(E, c)=c_{i}-d_{i}=\psi_{i}^{w}(N, E, c, a, w)$.

(c) Order Preservation Under Claims Variations

We note for any $i \in N$ that $\psi_{i}^{w}\left(N, E, c^{\prime}, a, w\right)-\psi_{i}{ }^{w}(N, E, c, a, w)=-\left[1-\frac{w_{k} a_{k}}{\sum_{j \in N} w_{j} a_{j}}\right]$ $\frac{\left(c_{k}^{\prime}-c_{k}\right)}{{ }_{n-1=\psi_{j}^{w}}\left(N, E, c^{\prime}, a, w\right)-\psi_{j}^{w}(N, E, c, a, w) .}$

(d) Super Modularity

$$
\begin{aligned}
& \text { Since } w_{i} a_{i}=w_{j} a_{j}, \\
& \frac{\psi_{j}{ }^{w}\left(N, E^{\prime}, c, a^{\prime}, w\right)-\psi_{j}{ }^{w}(N, E, c, a, w)=\left[1-\left(\frac{w_{j} a_{j}}{\sum_{j \in N} w_{j} a_{j}}\right)\right]}{\left(E^{\prime}-E\right)} \frac{\text { have, }}{n^{\prime}-1=\left[1-\left(\frac{w_{i} a_{i}}{\sum_{i \in N} w_{i} a_{i}}\right)\right]} \\
& \frac{\psi_{i}{ }^{w}\left(N, E^{\prime}, c, a^{\prime}, w\right)-\psi_{i}{ }^{w}(N, E, c, a, w) .}{}
\end{aligned}
$$

(e) Linked Monotonicity

Let $C=\sum_{i=1}^{n} c_{i}, E=\sum_{i=1}^{n} a_{i}$ and $D=C$-E. Since $a^{\prime}=\left(a_{1}+\alpha_{1}, a_{2}+\alpha_{2}, \ldots, a_{i}, \ldots, a_{n}+\alpha_{n}\right)$ such that $\sum_{j \in N \backslash\{i\}} \alpha_{j}=\alpha$, we have for any $i \in N, \psi_{i}^{w}\left(N, E+\alpha,\left(c_{i}+\alpha, c_{-i}\right), a^{\prime}, w\right)=c_{i}+\alpha^{-}$ $\left[1-\frac{w_{i} a_{i}}{\sum_{j \in N} w_{j} a_{j}}+\sum_{j \in N \backslash\{i\}} w_{j} \alpha_{j}\right] \quad \frac{(C-E)}{N-1 \leq c_{i}+\alpha-\frac{\left[1-\frac{w_{i} a_{i}}{\sum_{j \in N} w_{j} a_{j}}\right] D}{N-1}=\psi_{i}{ }^{w}(N, E, c, a, w)+\alpha .}$

Thus, $\psi_{i}^{w}\left(N, E+\alpha,\left(c_{i}+\alpha, c_{-i}\right), a^{\prime}, w\right)-\psi_{i}^{w}(N, E, c, a, w) \leq \alpha$. 
(f) Path Independence

Since $\frac{a_{i}^{\prime}}{a_{i}}=\frac{E^{\prime}}{E}, \forall i \in N$ such that $E^{\prime} \geq E$, we have for any $i \in N, \psi_{i}^{w}\left(N, E^{\prime}, c, a^{\prime}, w\right)=\psi_{i}^{w}$ $(N, E, c, a, w)+\left[1-\left(\frac{w_{i} a_{i}}{\sum_{j \in N} w_{j} a_{j}}\right)\right] \frac{\left(E^{\prime}-E\right)}{n-1 .}$

Now note that $\sum_{i=1}^{n} \psi_{i}{ }^{w}\left(N, E^{\prime}, c, a^{\prime}, w\right)=E^{\prime}$.

Further, $\psi_{i}^{w}\left(N, E, \psi^{w}\left(N, E^{\prime}, c, a^{\prime}, w\right), a, w\right)=\psi_{i}^{w}\left(N, E^{\prime}, c, a^{\prime}, w\right)-\left[1-\left(\frac{w_{i} a_{i}}{\sum_{j \in N} w_{j} a_{j}}\right)\right]$ $\frac{\left(\sum_{i=1}^{n} \psi_{i}^{w}\left(N, E^{\prime}, c, a^{\prime}, w\right)-E\right)}{n-1}=\psi_{i}^{w}(N, E, c, a, w)+\left[1-\left(\frac{w_{i} a_{i}}{\sum_{j \in N} w_{j} a_{j}}\right)\right]$ $\frac{\left(\sum_{i=1}^{n} \psi_{i}^{w}\left(N, E^{\prime}, c, a^{\prime}, w\right)-E\right)}{n-1}=\psi_{i}^{w}(N, E, c, a, w)+\left[1-\left(\frac{w_{i} a_{i}}{\sum_{j \in N} w_{j} a_{j}}\right)\right]$ $\frac{\left(E^{\prime}-E\right)}{n-1-\left[1-\left(\frac{w_{i} a_{i}}{\sum_{j \in N} w_{j} a_{j}}\right)\right]}$ $\frac{\left(E^{\prime}-E\right)}{n^{-1}}=\psi_{i}^{w}(N, E, c, a, w)$

Thus, $\psi_{i}^{w}\left(N, E, \psi^{w}\left(N, E^{\prime}, c, a^{\prime}, w\right), a, w\right)=\psi_{i}^{w}(N, E, c, a, w)$.

Open Access This article is distributed under the terms of the Creative Commons Attribution License which permits any use, distribution, and reproduction in any medium, provided the original author(s) and the source are credited.

\section{References}

Altinbilek D (1997) Water and land resources development in Southeastern Turkey. Int J Water Resour Dev 13: 311-332. doi:10.1080/07900629749719

Altinbilek D (2004) Development and management of the Euphrates-Tigris basin. Int J Water Resour Dev 20: 15-33. doi:10.1080/07900620310001635584

Ambec S, Ehlers L (2008) Cooperation and equity in the river sharing problem. In: Dinar A, Albiac J, Sánchez-Soriano J (eds) Game Theory Policy Mak. Nat. Resour. Environ. Routledge Publishers, pp 112-131

Ambec S, Sprumont Y (2002) Sharing a River. J Econ Theory 107:453-462. doi:10.1006/jeth.2001.2949

Ambec S, Dinar A, McKinney D (2013) Water sharing agreements sustainable to reduced flows. J Environ Econ Manag 66:639-655. doi:10.1016/j.jeem.2013.06.003

Ansink E (2009) Game-theoretic models of water allocation in transboundary river basins. PhD Dissertation, Wageningen University

Ansink E, Marchiori C (2010) Reallocating water: an application of sequential sharing rules to Cyprus. FEEM Work Pap No 126(20):1-19. doi:10.2139/ssrn.1533288

Ansink E, Weikard H-P (2012) Sequential sharing rules for river sharing problems. Soc Choice Welfare 38:187210. doi:10.1007/s00355-010-0525-y

Bagis AI (1989) GAP: Southeastern Anatolia project -the cradle of civilisation regenerated. Interbank Yayinlari, Istanbul

Beaumont P (1998) Restructuring of water usage in the Tigris-Euphrates Basin: The impact of modern water management policies. In: Albert J, Bernhardsson M, Kenna R (eds) Transform. Middle East. Nat. Environ. Legacies Lessons. Bull. Ser. No. 103. Yale School of Forestry and Environmental Studies, New Haven, CT, pp 168-186 
Bilen O (1994) Prospects for technical cooperation in the Euphrates-Tigris Basin. In: Biswas AK (ed) Int. Waters Middle East from Euphrates-Tigris to Nile. Oxford University Press, Oxford, p 240

Bosmans K, Lauwers L (2011) Lorenz comparisons of nine rules for the adjudication of conflicting claims. Int J Game Theory 40:791-807. doi:10.1007/s00182-010-0269-z

Casas-Méndez B, Fragnelli V, García-Jurado I (2011) Weighted bankruptcy rules and the museum pass problem. Eur J Oper Res 215:161-168. doi:10.1016/j.ejor.2011.05.033

Curiel IJ, Maschler M, Tijs SH (1987) Bankruptcy games. Zeitschrift für Oper Res 31:A143-A159. doi:10.1007/ BF02109593

Dagan N (1996) New characterizations of old bankruptcy rules. Soc Choice Welfare 13:51-59. doi:10.1007/ BF00179098

Dagan N, Serrano R, Volij O (1997) A noncooperative view of consistent bankruptcy rules. Games Econ Behav 18:55-72. doi:10.1006/game.1997.0526

De Stefano L, Duncan J, Dinar S et al (2012) Climate change and the institutional resilience of international river basins. J Peace Res 49:193-209. doi:10.1177/0022343311427416

Dinar A, Nigatu GS (2013) Distributional considerations of international water resources under externality: the case of Ethiopia, Sudan and Egypt on the Blue Nile. Water Resour Econ 2-3:1-16. doi:10.1016/j.wre.2013. 07.001

Dinar A, Ratner A, Yaron D (1992) Evaluating cooperative game theory in water resources. Theory Decis 32:120. doi:10.1007/BF00133625

FAO-AQUASTAT (2009) Euphrates-Tigris river basin. In: FAO’s Inf. Syst. Water Agric. http://www.fao.org/nr/ water/aquastat/basins/euphrates-tigris/index.stm. Accessed 25 Oct 2013

Fuentes X (1997) The criteria for the equitable utilization of international rivers. Br Yearb Int Law 67:337-412. doi:10.1093/bybil/67.1.337

Gallastegui MC, Iñarra E, Prellezo R (2002) Bankruptcy of fishing resources: the Northern European Anglerfish Fishery. Mar Resour Econ 17:291-307

Granit J, Joyce J (2012) Options for cooperative action in the Euphrates and Tigris Region. SIWI Paper:36

Herrero C, Villar A (2001) The three musketeers: four classical solutions to bankruptcy problems. Math Soc Sci 42:307-328. doi:10.1016/S0165-4896(01)00075-0

Hokari T, Thomson W (2003) Claims problems and weighted generalizations of the Talmud rule. Econ Theory 21:241-261. doi:10.1007/s00199-002-0314-7

Ibrahim G, Sonmez B (2002) Water issues among the riparian states of Euphrates and Tigris transboundary rivers. In: Castelein S (ed) From confl. to co-operation Int. Water Resour. Manag. Challenges Oppor. UNESCO, Delft, pp 278-286

Just RE, Netanyahu S (1998) International water resource conflicts: experience and potential. In: Netanyahu S, Just RE (eds) Confl. Coop. Transbound. Water Resour. Kluwer Academic Publishers, Boston, pp 1-26

Kalai E, Samet D (1987) On weighted Shapley values. Int J Game Theory 16:205-222

Kaya I (1998) The Euphrates-Tigris basin: An overview and opportunities for cooperation under international law. In: Arid Lands Newsl. https://ag.arizona.edu/OALS/ALN/aln44/kaya.html. Accessed 25 Oct 2013

Kliot N (1994) Water resources and conflict in the Middle East. Prog Hum Geogr 24:309

Kolars J (1994) Problems of International River Management: case of Euphrates and Tigris. In: Biswas AK (ed) Int. waters Middle East -frome Euphrates -Tigris to Nile. Oxford University Press, Oxford, pp 44-94

Kolars J, Mitchell WA (1991) The Euphrates River and the Southeast Anatolia Development Project: Water: The Middle East Imperative (Stimulus Book). 360

Kucukmehmetoglu M (2009) A game theoretic approach to assess the impacts of major investments on transboundary water resources: the case of the Euphrates and Tigris. Water Resour Manag 23:3069-3099. doi:10.1007/s11269-009-9424-3

Lee NC (1994) A simple generalization of the constrained equal award rule and its characterization. mimeo 62

Lehner B, Verdin K, Jarvis A (2008) New global hydrography derived from spaceborne elevation data. EOS Trans Am Geophys Union 89:93-94. doi:10.1029/2008EO100001

Li XY (2009) Research on on-demand optimal computaion based on emergency decision-making of unusual emergency event. Dissertation, Chinese Academy of Sciences

Lupu Y (2002) International law and the waters of the Euphrates and Tigris. Georg Int Environ Law Rev 14:349366

MacQuarrie P (2004) Water security in the middle east: growing conflict over development in the EuphratesTigris basin. Trinity Coll Dublin 84

Madani K, Zarezadeh M, Morid S (2014) A new framework for resolving conflicts over transboundary rivers using bankruptcy methods. Hydrol Earth Syst Sci 18:3055-3068. doi:10.5194/hess-18-3055-2014

McCarthy N, Sadoulet E, de Janvry A (2001) Common pool resource appropriation under costly cooperation. J Environ Econ Manag 42:297-309. doi:10.1006/jeem.2000.1164 
McIntyre O (2013) Utilization of shared international freshwater resources - the meaning and role of "equity" in international water law. Water Int 38:112-129. doi:10.1080/02508060.2013.779199

Mianabadi H, Mostert E, Zarghami M, van de Giesen N (2014a) A new bankruptcy method for conflict resolution in water resources allocation. J Environ Manag 144:152-159. doi:10.1016/j.jenvman.2014.05.018

Mianabadi H, Sheikhmohammady M, Mostert E, Giesen N (2014b) Application of the Ordered Weighted Averaging (OWA) method to the Caspian Sea conflict. Stoch Environ Res Risk Assess. doi:10.1007/ s00477-014-0861-z

Moulin H (1987) Equal or proportional division of a surplus, and other methods. Int J Game Theory 16:161-186. doi:10.1007/BF01756289

Moulin H (2000) Priority rules and other asymmetric rationing methods. Econometrica 68:643-684

Pande S, Ertsen M (2014) Endogenous change: on cooperation and water availability in two ancient societies. Hydrol Earth Syst Sci 18:1745-1760. doi:10.5194/hess-18-1745-2014

Pande S, McKee M (2007) Valuing certainty in a consensus-based water allocation mechanism. Water Resour Res 43:1-13. doi:10.1029/2004WR003890

Savenije HHG, van der Zaag P (2000) Conceptual framework for the management of shared river basins; with special reference to the SADC and EU. Water Policy 2:9-45. doi:10.1016/S1366-7017(99)00021-5

Schulz M (1995) Turkey, Syria, and Iraq: a hydropolitical security complex - the case of Euphrates and Tigris. In: Ohlsson L (ed) Hydropolitics conflicts over water as a dev. Constraint. Zed Books, London, pp 91-122

Shapley LS (1953) A value for n-person games. Contrib Theor Games 2:307-317

Sheikhmohammady M, Madani K (2008) Sharing a multi-national resource through bankruptcy procedures. In: Babcock Jr RW, Walton R (eds) World Environ. Water Resour. Congr. 2008 Ahupua'a. ASCE, Honolulu, Hawaii, pp 556-556

Swain A (2001) Water wars: fact or fiction? Futures 33:769-781. doi:10.1016/S0016-3287(01)00018-0

Thomson W (2003) Axiomatic and game-theoretic analysis of bankruptcy and taxation problems: a survey. Math Soc Sci 45:249-297. doi:10.1016/S0165-4896(02)00070-7

Thomson W (2009) How to divide when there isn't enough: From the Talmud to game theory. Book manuscript, University of Rochester

Tomanbay M (2000) Turkey's approach to utilization of the Euphrates and Tigris rivers. Arab Stud Q 22:79-100

Wolf AT (1999) Criteria for equitable allocations: the heart of international water conflict. Nat Resour Forum 23: 3-30. doi:10.1111/j.1477-8947.1999.tb00235.x

Xia X, Cui J (2009) Study of water resource allocation mechanism. Eighth Int. Symp. Oper. Res. Its Appl. Zhangjiajie, China, pp 212-219

Young H (1988) Distributive justice in taxation. J Econ Theory 44:321-335. doi:10.1016/0022-0531(88)90007-5

Zarezadeh M, Madani K, Morid S (2012) Resolving transboundary water conflicts: lessons learned from the Qezelozan-Sefidrood river bankruptcy problem. World Environ. Water Resour. Congr. 2012. American Society of Civil Engineers, Reston, pp 2406-2412

Zawahri NA (2006) Stabilising Iraq's water supply: what the Euphrates and Tigris rivers can learn from the Indus. Third World Q 27:1041-1058. doi:10.1080/01436590600850467

Zentner MA (2010) Assessing the design of international water supply and hydropower arrangements for managing certain climate change scenarios. PhD Dissertation, Oregon State University 